\title{
ASO Visual Abstract: Guide to Enhanced Recovery for Cancer Patients Undergoing Surgery for Head and Neck Cancer
}

\author{
Anirudh Saraswathula, MD, MS, Christine G. Gourin, MD, MPH, FACS, and Peter S. Vosler, MD, PhD \\ Department of Otolaryngology-Head and Neck Surgery, Johns Hopkins University School of Medicine, Baltimore, MD
}

Enhanced Recovery After Surgery ${ }^{\circledR}$ (ERAS) programs provide a structured and evidence-based framework for major surgery along the entire care continuum. Unique aspects of ERAS programs in head and neck cancer surgery include preadmission planning for patient education regarding surgery and postoperative care, ensuring multidisciplinary care with speech and language therapists, carefully managing the use of free flap reconstruction and postoperative monitoring, placement and removal of tracheostomy tubes, and considering the need for feeding tubes to bypass the surgical defect to provide early postoperative nutrition. These programs have been shown in head and neck surgery to reduce length of stay (LOS) and morbidity without sacrificing postoperative outcomes (https://doi.org/10.1245/s10434-0 21-10029-7).

\section{Summary of Items in Head and Neck Cancer ERAS ${ }^{\circledR}$ Pathway}

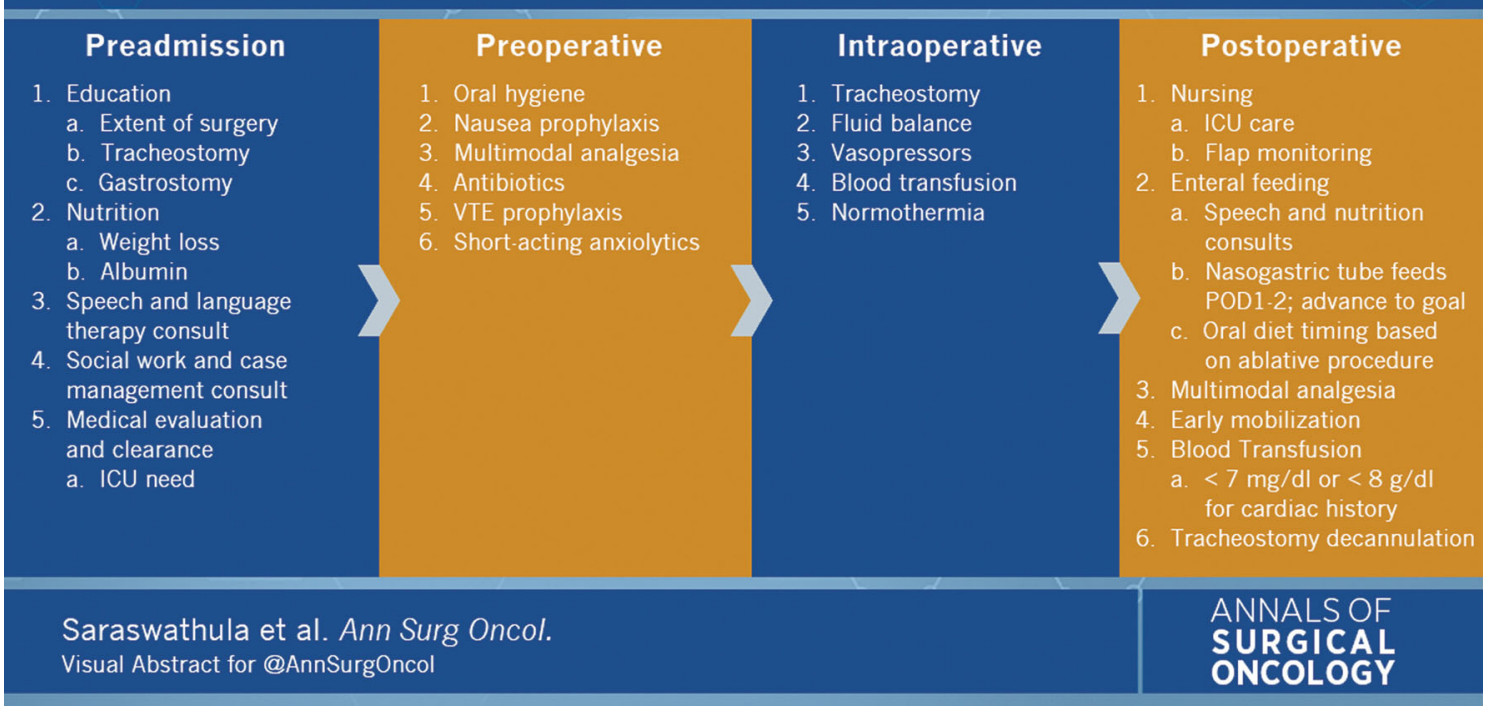

(C) Society of Surgical Oncology 2021

Publisher's Note Springer Nature remains neutral with regard to jurisdictional claims in published maps and institutional affiliations.

Published Online: 20 May 2021

P. S. Vosler, MD, PhD

e-mail: pvosler1@jhmi.edu 